\title{
A FILOSOFIA EM SEUS EXTREMOS: DE PLATÃO A MERLEAU-PONTY
}

Jayme Paviani*

SÍNTESE - Este ensaio aborda possiveis aproximaçōes e afastamento entre as filosofias de Platão e de Merleau-Ponty, especialmente entre a fundação de uma ontologia inteligivel em Platão e a inauguração de uma ontologia sensivel ou selvagem em M. Merleau-Ponty.

PALAVRAS-CHAVE - Platão. Merleau-Ponty. Ontologia inteligivel. Ontologia sensivel.
ABSTRACT - This essay examines possible rapprochements and divergencies between Plato's and Merleau-Ponty's philosophies, especially between the grounding of an intelligible ontology in Plato and the inauguration of a sensible ontology in M. Merleau-Ponty.

KEY WORDS - Plato. Merleau-Ponty. Intelligible ontology. Sensible ontology.

Merleau-Ponty não dedica uma atenção especial a Platão nem sequer à filosofia grega. Raras vezes menciona o filósofo em șeus escritos. Quando o faz, referese a ele de modo indireto. Entretanto, a relação entre um filósofo fundador do pensamento metafísico, como Platão (ou Aristóteles), e um filósofo, como M. Merleau-Ponty que busca a superação dos sistemas filosóficos do Ocidente, não está apenas nos aspectos exteriores, nas possíveis citações, numa certa proximidade ou distanciamento no modo de investigar as questões. As relações entre os filósofos, no sentido radical, fazem-se nos modos de pensar e nos motivos universais de cada filosofia. Os diferentes contextos históricos e os movimentos dos atoresfilósofos, na sucessão das filosofias, pressupõem desejos e interesses, vontades e indagações que dão sentido às questões fundamentais.

A aproximação ou o distanciamento entre Platão e Merleau-Ponty está no filosofar e não nas suas filosofias. As "heranças" na história da filosofia fecundam o pensar e pouco importa o conteúdo dos enunciados. Do mesmo modo que a separação entre platônicos e aristotélicos ignora as relações fundadoras e internas que os unem, não podemos ignorar a linha que percorre o início do pensamento grego até o "fracasso" ou a consumação da filosofia no século XX. Nesse sentido, o pensamento pontyano reconhece que há uma linguagem comum a todas as filoso-

* Doutor. Professor da UCS (Universidade de Caxias do Sul) e da PUCRS (Pontifícia Universidade Católica do Rio Grande do Sul).

\begin{tabular}{|l|l|l|l|l|l|}
\hline VERITAS & Porto Alegre & v. 49 & n. 4 & Dezembro 2004 & p. 751-762 \\
\hline
\end{tabular}


fias (1984, p. 235) e que há uma história "objetiva" que mutila os grandes filósofos "naquilo que deram aos outros para pensar", pois deve haver "um espaço onde 0 filósofo de que se fala e aquele que fala" seja comum a ambos, embora seja impossível repartir a cada momento o que é de cada um" (1984, p. 239-241).

Os textos filosóficos, além de aspectos externos e circunstanciais, têm a força de inaugurar, de modo permanente, com novas interrogações, as questões nucleares postas pelos pré-socráticos. Desde sempre a filosofia começa de novo em cada filósofo. A tarefa do filósofo é a de recriar e esclarecer (construir e desconstruir) os conceitos fundamentais sobre a natureza e a liberdade, sobre o ser humano no mundo. A articulação das primeiras questões operada por Platão, em seus diálogos, não cessa de pensar os princípios e as teorias que descrevem e explicam a origem e a natureza do homem e do mundo e os campos semânticos dos termos logos e physis, ser e parecer, ser e não-ser, ser e nada, uno e múltiplo, doxa e episteme, natureza e cultura, ética e estética e outras implicações derivadas dessas questōes.

Hoje parece fácil desenvolver estudos historiográficos e analíticos dos textos clássicos, todavia continua sendo um desafio a busca de sentido ou de soluções para as questões filosóficas centrais revividas na contemporaneidade. $\mathrm{Na}$ realidade, investigar aspectos lingüísticos, lógicos, semânticos, ideológicos, exige menos empenho especulativo do que refletir sobre essas questões na crescente complexidade que perpassa a vida contemporânea. Isso se deve ao fato de a filosofia ser constituída por um pensamento que vai além do histórico e do biográfico. Hoje compreender o sentido da "boa ambigüidade" da linguagem, inclusive da metafísica, é tăo importante quanto o esclarecimento lógico dos conceitos e dos enunciados.

O processo constitutivo da filosofia de Platão, sob a denominação geral de metafísica (termo que adiante será examinado), é desconstruído pelo processo fenomenológico-ontológico de Merleau-Ponty. Estamos diante de um pensamento fundador e de um pensamento "destruidor" da metafísica. Nesse sentido, o esforço radical de Merleau-Ponty de buscar as raízes esquecidas das estruturas da metafísica grega acaba certamente numa espécie de fracasso epistemológico, mas, por sua vez, o retorno "às coisas mesmas" (de Husserl), a descrição ou intuição do conhecimento do mundo anterior ao conhecimento objetivo da ciência do mundo, o acesso ao conhecimento do mundo vivido, do pensamento pré-teórico, restitui o vigor primitivo do filosofar.

Talvez não se possa falar em progresso na filosofia (conceito problemático também em relação à ciência). Não existe um aumento numérico de conhecimentos filosóficos. A filosofia não fornece informações relevantes capazes de resolver problemas imediatos dos indivíduos e da sociedade. A filosofia simplesmente põe em questão (e ação) modalidades e possibilidades de conhecer e dizer as coisas ou o mundo. O pensamento filosófico é cíclico (no sentido hermenêutico e, ao mesmo tempo, analítico e dialético), gira em torno das mesmas questões fundamentais, sempre dentro de novos horizontes. 
No início da filosofia, na Grécia antiga, encontramos as teorias de Platão, de Aristóteles, as posições do ceticismo, do relativismo, do estoicismo e outras. Em Platão, na primeira grande filosofia escrita, num total de 36 textos, a comunicação filosófica privilegia o diálogo e a oralidade como modalidades exemplares de acesso ao bem, às idéias, à justiça e à verdade. Sua argumentação dialética parte de teses apriorísticas, de pressupostos não-tematizados. Em Merleau-Ponty, o esforço teórico e metodológico consiste no reexame do mundo da doxa, da percepção "sensível", do corpo próprio, dos sentidos da expressão. Essa busca radical e penosa pretende encontrar os limites entre o sensivel e o inteligivel, o uno e o múltiplo. Quer, em outras palavras, explorar o mundo que a metafísica pôs de lado ou pôs fora. Quer recolocar as essências na existência. Quer identificar as origens do conhecimento inteligivel nos fenômenos da percepção e da expressão.

Esses dois estilos de pensamento parecem nos conduzir por caminhos diferentes. Para saber qual a aproximação ou a distância que existe entre eles, é útil metodologicamente considerar alguns pontos de referência, como (a) a teoria platônica do conhecimento, da linguagem e da realidade no entrecruzamento dialético da doxa e da episteme (tematizada na República, no Teeteto e em outros diálogos), em confronto com a descrição fenomenológica da percepção, da expressão e da visão, (no percurso da Fenomenologia da Percepção, de Signos e de O visivel e o invisivel). Também é útil considerar (b) a questão específica do método, isto é, dos processos dialéticos de Platão e de Merleau-Ponty. Pode-se, igualmente, (c) examinar as ontologias e as contribuições ético-estético-antropológicas de cada um. Percebe-se, desde um primeiro olhar, as diferentes maneiras de conceber a realidade, o visivel e o invisível, o corpo e a alma (mente, consciência), o humano, o divino e o universo.

Nesse enquadramento metódico merece prioridade a caracterização da ontologia do inteligivel de Platão e da ontologia do sensivel de Merleau-Ponty. A gênese da ontologia platônica, em contrapartida com as críticas pontyanas a essa ontologia e o correspondente esboço de uma ontologia do ser selvagem, talvez mostre o núcleo e o sentido da experiência que originou o pensamento metafísico e preparou igualmente a sua superação. Qual o ganho dessa aposta especulativa? Talvez uma explicação do esgotamento formal e histórico das filosofias que permitiram a redução de seus conceitos a simples esquemas explicativos.

Desse confronto dialético também surgem os modos diferentes de conceber a linguagem e o conhecimento. Platão expressou no Fedro e na Sétima Carta sua desconfiança na objetividade da escrita. Para ele a oralidade e a maturidade humana são os canais e as condições do filosofar capazes de alcançar as essências, a verdade e o bem. Porém, sua compreensão da linguagem e do conhecimento permanece refém de uma visão metafísica pré-determinada. Merleau-Ponty, na outra ponta da racionalidade ocidental, também cultiva o gosto pela evidência, mas se distancia de Platão ao afirmar que "aqueles que pretenderam construir uma filosofia absolutamente positiva só conseguiram ser filósofos, na medida em que, simultaneamente, se recusaram o direito de se instalar no saber absoluto [...]" (Elogio da Filosofia, p. 10 e 11). Para ele, a escrita e a linguagem não são simples instrumentos do pensamento e do raciocínio, mas expressão significativa e articulada do ser das coisas. 
Platão parte de princípios e entidades ou idéias objetivas, imutáveis, eternas, pré-existentes ao mundo sensivel. Para Merleau-Ponty uma filosofia que parte do a priori apenas "sobrevoa" a experiência humana, pois é exatamente na aceitação ou não do a priori ou da noção de fundamentos últimos que se entrecruza a possibilidade ou não de um pensamento metafísico.

Platão parte de um mundo inteligivel pré-existente, de proposições válidas a priori, que não podem ser negadas pela experiência. Com elas quer explicar a unidade do ser e a multiplicidade dos entes, os modos de não-ser. Ao procurar, nos primeiros diálogos, as definições da idéia de justiça, de coragem, de beleza, de piedade, enfrenta o problema da unidade e da multiplicidade. Mas a questão de fato pressupõe uma solução prévia. No Mênon, por exemplo, adverte que não é possivel investigar aquilo que se sabe nem aquilo que não se sabe, pois o que se sabe não é necessário procurar e aquilo que não se sabe é inútil tentar saber. Argumentos heurísticos como esse têm origem na concepção parmenidiana sobre o ser e o não-ser. Sua tarefa é demonstrar dialeticamente a tese desde sempre dada, como ele diz, em certas passagens (cf. Filebo), pelos deuses.

Merleau-Ponty propõe a fé perceptiva como ponto de partida, mergulha radicalmente na compreensão do sensível, do múltiplo, nos fenômenos postos em segundo plano por Platão e, mais tarde, por Kant e Hegel. Não aceita o estilo dedutivo e explicativo de uma filosofia constituída. Para ele, o movimento entre saber e ignorância só é legítimo quando passa pelo "interior" das filosofias e não pelo seu "exterior".

Merleau-Ponty, citando Husserl, afirma que a tradição é o esquecimento das origens. Nessa perspectiva, o sentido da expressão "destruição da metafísica" assume em Merleau-Ponty um sentido radical. Indo além da analítica existencial do cotidiano, ele descreve fenomenologicamente os fenômenos do corpo próprio e da percepção e, desse modo, prepara uma ontologia do sensível. A metafísica é posta ao avesso, ao procurar, nas filosofias objetivadas de Platão, de Aristóteles, de Leibniz, de Espinosa, de Kant e de Hegel, uma parte esquecida da experiência do filosofar.

Platão, para fundar a filosofia, afasta-se do mundo empírico. Merleau-Ponty parte da experiência do vivido, mesmo que para isso tenha de tentar objetivos epistemologicamente impossíveis. Assume de certo modo a experiência da ambigüidade e do fracasso, os limites da racionalidade. Depois de séculos de objetivação, investiga o sentido do ser no mundo sensivel. O corpo próprio, e não apenas a consciência, é lugar de explosão do sentido do ser. A unidade do ser bruto está na multiplicidade sensivel, no vivido.

Platão apresenta talvez o primeiro esboço de uma sistematização da ontologia do inteligivel. Merleau-Ponty, na obra inacabada $O$ Visível e o Invisivel, procura elaborar uma ontologia às avessas da filosofia clássica. É o mundo da vida, e não o mundo das idéias, que prenuncia uma nova ontologia. A idéia de bem e os gêneros supremos (ser, repouso, movimento, identidade, diferença, finito, infinito, causa) expostos no Sofista, no Filebo e no Timeu são, sem dúvida, os pontos mais altos de sua explicação dialética do ser e do não-ser, do uno e do múltiplo. 
Merleau-Ponty busca o sentido originário da realidade, primeiro (a) na descrição fenomenológica do corpo e da percepção, depois (b) na expressão, e, finalmente, numa nova investigação ontológica noção de (c) visão, na reversibilidade do ser proposto em Visível e Invisivel.

Platão chega a uma ontologia após esgotar a dialética sofistica e socrática. A dialética pontyana, com o perfil de uma dialética hegeliana difusa, pretende alcançar o lugar anterior a todos os opostos ou contradições. A dialética platônica quer superar os opostos apelando aos "princípios metafísicos" (diriamos hoje) e ao mundo do inteligível, a partir de um ponto de vista objetivante. O pensamento pontyano aceita a boa ambigüidade da linguagem e, em conseqüência, do mundo.

\section{A metafísica e a experiência do filosofar}

Falar do início e do fim históricos da metafísica pressupõe o esclarecimento do sentido do termo metafísica, dos seus diferentes significados efetivados nos grandes sistemas filosóficos, desde Platão até Hegel. Em linhas gerais, a metafísica tem como pressuposto a existência de um a priori, de um absoluto externo ao mundo e a pretensão de abarcar a totalidade do real, ao descrever o essencial sobre Deus, o homem e o universo ou, simplesmente, ao explicar as características mais gerais do mundo. O pensamento metafisico, via de regra, separa o mundo inteligível do mundo sensivel.

Uma das primeiras questões da metafísica consiste em esclarecer o ser em relação ao ente enquanto ente, cerne de toda ontologia, isto é, da teoria da existência (substância) e da essência das coisas. Investiga a realidade como evento, fato, estado, propriedade, necessidade, contingência, possibilidade, causalidade, tempo, espaço. Todas essas categorias ontológicas têm seus pressupostos em princípios metafísicos como o uno e o múltiplo, o sensível e o inteligivel.

Platão é um dos primeiros a distinguir o mundo inteligivel do mundo sensivel e tirar disso inúmeras conseqüências. Aristóteles investiga as primeiras causas ou princípios e elabora a ciência do ente enquanto ente. Para Kant, a metafísica é um conhecimento racional especulativo que está acima da experiência e se apóia apenas em simples conceitos. A metafísica insatisfeita com os dados da experiência busca condições absolutas, incondicionadas e, por isso, as realidades metafísicas só podem ser pensadas, jamais conhecidas. É o que ocorre com a busca de soluções para os problemas de Deus, da liberdade e da imortalidade.

A ciência hoje (que surgiu tradicionalmente dos paradigmas metafísicos) superou em grande parte diversos problemas metafísicos. A metafísica, seja ela revisionista ou descritiva como quer Strawson, é submetida a um conjunto de críticas cerradas. Se antes do Iuminismo a metafisica era dominada pela teologia, depois continuou refém de um ser superior, racional e inteligente. A especulação no idealismo não cessou de uni-la a uma visão religiosa. O positivismo fracassou na tentativa de matar totalmente o pensamento metafísico. Realistas e idealistas, de diversos matizes, e os esforços modernos desde Frege e Wittgenstein até Nietzsche, Marx e Heidegger não conseguem eliminar todos os traços da metafisica na época contemporânea. 
Por isso, falar sobre o início e o fim da metafísica exige razões e distinções. Início pode significar começo e também fundamento. Fim pode significar término, mas também conclusão, realização ou esgotamento. Feita essa ressalva, apesar de todas as proclamações a respeito do fim da metafísica, pode-se constatar que ela ainda subsiste. Assim, para Merleau-Ponty, nos extremos do pensamento clássico, a metafísica ainda pode subsistir desde que, "deixando de viver na evidência do objeto", se torne possivel perceber indissoluvelmente a subjetividade radical de toda nossa experiência e seu valor de verdade (O metafísico no homem, 1984, p. 178 a 192).

O próprio pensamento de Merleau-Ponty, nem sempre livre de resquícios metafísicos, especialmente em suas primeiras obras, é um dos exemplos possiveis de um esforço de superação do modo de pensar metafísico. No entanto, ele reconhece que cada um pode dizer qual significação o termo metafísica ainda possui hoje. (Há um significado latente). Ele afirma que a metafísica, "reduzida pelo kantismo ao sistema de princípios empregados pela razão na constituição da ciência ou do universo moral, radicalmente contestada, nesta função diretriz, pelo positivismo, não cessou de levar uma espécie de vida clandestina na literatura e na poesia, onde hoje os críticos a reencontram" (1984, p. 179). A metafísica reaparece nas ciências, especialmente nas ciências do homem, nas manifestações artísticas, na moral, na religião. Por isso, Merleau-Ponty, ao criticá-la, ao examinar seus pressupostos, além de circunscrevê-la em suas realizações concretas, deseja descobri-la em seus "vinculos secretos" que ligam o homem moderno com o homem da caverna e graças aos quais "Platão ainda vive entre nós".

Sendo a experiência do filosofar, ao mesmo tempo, pessoal e histórica, a questão do início e da consumação da metafísica permite ver como os problemas filosóficos, os conceitos fundamentais se desenvolvem e carregam consigo, sob a nostalgia das palavras, a dimensão da universalidade sem perder o pó ou o mofo dos séculos, as contingências de cada época. As filosofias do passado, diz Merleau-Ponty, "perduram com suas verdades e suas loucuras, como empreendimentos totais, ou não perduram de modo algum". "O próprio Hegel, essa cabeça que quis conter o Ser, vive hoje e nos faz pensar não só por suas profundidades, mas também por suas manias e seus tiques. Não há uma filosofia que contenha todas as filosofias: a filosofia inteira está, em certos momentos, em cada uma delas. Repetindo a famosa expressão, seu centro está em toda parte e sua circunferência em parte nenhuma" (Signos, 1991, p. 139 e 140).

Não é justo ler e estudar os filósofos considerando apenas suas grandes contribuiçöes ético-políticos e gnosio-ontológicos para a civilização; também é necessário refletir sobre seus fracassos, sobre as contingências da história da filosofia. A filosofia é um produto da cultura, apesar de seus altos vôos ou justamente devido aos seus interesses desmedidos. A filosofia não é um saber isolado, ao contrário, é um ponto de vigilância do saber. Ela não se apropria dos objetos. "Pensar, diz Merlau-Ponty, não é possuir objetos de pensamentos; é circunscrever, graças a eles, domínio para pensar o que, portanto, ainda não foi pensado". E, logo acrescenta: "a obra e o pensamento de um filósofo são feitos de certas articulações 
entre as coisas ditas, frente às quais não há dilema entre a interpretação objetiva e a arbitrária, visto que ali não estão objetos de pensamentos, pois, como a sombra e o reflexo, também eles seriam destruídos se submetidos à observação analítica ou ao pensamento isolante" (1984, p. 241-242). Para reencontrar o pensamento e a obra de um filósofo, é preciso "pensar de novo" e, isso vale tanto para Platão quanto para Merleau-Ponty ou qualquer outro filósofo.

\section{A ontologia do inteligível e a ontologia do sensível}

Platão, no Fedro, afirma que a dialética investiga a essência (ousia) de cada coisa. Na República, ao projetar o Estado ideal, procura definir a idéia de justiça correspondente. No Sofista, reflete sobre a questão do ser e do não ser e a possibilidade de existir o discurso falso. Indaga o significado da palavra ser, significado que nos parece familiar e que todos pensam, desde sempre, compreender, mas que, de fato, nos deixa confusos. É necessário distinguir entre ser e parecer, entre o que simplesmente é e o que é o ser. A pronúncia da palavra ser nem sempre significa saber o que é que se quer dizer. Com essas primeiras aproximações sobre o ser, sobre os gêneros supremos e sobre a possibilidade do discurso falso, esboça-se a ontologia clássica mais tarde completada por Aristóteles.

Platão alicerça suas reflexões no princípio do bem, uma realidade que está além das essências. O bem ocupa um grau mais alto e puro do que o ser, o grau mais alto do conhecimento. O bem é distinto de qualquer outra coisa, fundamento do ser e do conhecer, é a lei ou a ordem pura do pensamento. Dele provém o critério da hierarquização dos objetos de conhecimento e dos graus do próprio conhecimento. Assim, no domínio da doxa, temos em primeiro lugar as imagens, objetos visíveis, eikasía, que são reflexos dos objetos da percepção sensivel, das crenças, pístis, produzidos pelo homem. No domínio do mundo inteligivel, da episteme, o raciocínio, dianóia, por meio de hipóteses, capta os objetos matemáticos. Mas a intelecção ou intuição pura, nóesis, alcançada, mediante a dialética, o bem. Nessa ordenação surge uma correspondência entre os graus do ser e os graus do conhecer (511 c - 534 a). Realidade, linguagem e conhecimento estão articulados de um modo quase arbitrário, apriorístico, sem nenhuma análise diairética. A relação entre nome e coisa, problematizada no diálogo Crátilo, é subsumida na estrutura da realidade inteligível e sensível. Os problemas expressos do ser, do uno e do múltiplo, do enunciado, do discurso falso, e outros aspectos dessa ontologia, são retomados nos diálogos Teeteto, Parmênides, Sofista, Político, Filebo com o avanço e o aperfeiçoamento dos processos dialéticos.

Depois dos versos (enunciados) de Parmênides sobre o ser, o não ser e o pensar, dos aforismos de Heráclito sobre o logos e devir, a afirmação de Protágoras de que o homem é a medida de todas as coisas, e de outras contribuições présocráticas socráticas e sofisticas, Platão examina as relações entre o uno e o múltiplo, o todo e as partes. E desses entrelaçamentos a metafísica funda a existência de Deus, da alma imortal, a natureza do conhecimento, da linguagem e da ação humana. 
A ontologia do inteligivel platônica é preparada por diversas incursões filosóficas nos diversos diálogos. No Mênon aparece o tema da unidade e da multiplicidade. No Crátilo, o problema da natureza do nome ligado ao problema do conhecimento das coisas. No Fédon, no Fedro, na República apresenta a teoria da idéias e da participação. No Teeteto, retorna ao problema do conhecimento. No Parmênides, critica a teoria das idéias e investiga o uno em si mesmo e o uno em relação aos múltiplos e observa que não há clareza sobre o termo ser. No Sofista reconstrói essas questões, numa nova articulação, com a ajuda do método diairétiCo, sem abandonar o processo refutativo. Procura elucidar a diferença entre o filósofo e o sofista, a partir das definições do sofista e da revisão das concepções do ser e do não ser e de suas implicações com os gêneros supremos e o discurso falso. Mas não é fácil perceber os movimentos dialéticos que envolvem as questöes suas repercussões na constituição de uma ontologia metafísica. O gênero diálogo colabora para que as questões não sejam apenas justapostas, mas articuladas dentro de um projeto ao mesmo tempo fechado, em seus pressupostos metafísicos, mas aberto às necessidades de uma reflexão esclarecedora.

O problema do não-ser (Sofista 237 b - 239 c) e suas dificuldades específicas (239 c - 242 b) é preparado por uma recepção das teorias do ser. Assim, os pluralistas (243 d - 244 b) definem o ser como dualidade: calor e frio, úmido e seco. Se ambos os opostos são, surge a seguinte indagação: o ser, por acaso, não seria um terceiro? Se cada um é, não se afirma duas vezes o uno? Se cada um é, não se chama de uno o que se refere a dois? Essa perspectiva coloca a necessidade de um terceiro e torna-se difícil explicar o que seja o uno e, ao mesmo tempo, justificar a pluralidade.

Para os unitaristas (244 b - 245 e), o ser e o uno são a mesma coisa. Mas chamar de ser o que se diz uno implica o uso de dois nomes para designar a mesma coisa e, desse modo, surge uma dualidade. De outro lado, se o nome não é a coisa, atribui-se ser a uma dualidade, e se o nome é idêntico à coisa, a coisa é o nome. Então o nome não passa de uma palavra, e, sendo o nome do uno idêntico ao uno, o uno absoluto é apenas a unidade da palavra. Se o uno é totalidade, é necessário que ele tenha partes. Porém, se algo é dividido em partes é, ao mesmo tempo, unidade e multiplicidade. Mas o uno, visto desse modo, não é o uno em si, o uno indivisível.

Os materialistas, os filhos da terra (Protágoras, Heráclito, Antístenes, os Cínicos e outros), afirmam que o que é, é corpóreo. Também a alma é corpórea. Apesar de não saberem explicar o que há de comum entre as coisas corpóreas e as incorpóreas, definem o ser como potência ativa (agir sobre) ou passiva (sofrer influência) (245 e - 2541 a). Os idealistas, os amigos das idéias (Espêusito, os Megários), pressupondo dois níveis de realidade: ser e devir, repouso e movimento, atividade e passividade, separam o corpo da alma. Segundo eles, só o devir participa da potência ativa e passiva. Examinando essas posições, Platão conclui que não se pode, como os primeiros, proclamar o movimento ilimitado, nem, como os segundos, afirmar a imobilidade de tudo. É exatamente a relação dos gêneros repouso e movimento, absolutamente contrários, que permite afirmar que ambos 
são, sem dizer que ambos estejam, ao mesmo tempo, em movimento ou em repouso. Platão, põe na "alma do ser" (tò ón en têi psychêi titheís, 250 b) uma espécie de terceiro (triton ti) que contém e engloba conjuntamente o repouso e o movimento, numa comunidade do "uno" e do outro com o ser, o qual não se reduz nem ao repouso nem ao movimento. Assim, com a participação do repouso e do movimento com o ser surge a comunidade dos gêneros supremos ( $251 \mathrm{a}-254$ b).

Assim temos três gêneros distintos, o ser, o repouso e o movimento, sendo que nenhum deles pode ser reduzido a um dos outros. Mas o problema da participação dos gêneros suscita o problema da predicação. É preciso que o dialético saiba distinguir os gêneros, embora não haja regras que combinem a totalidade dos gêneros e permitam elaborar uma gramática do ser. Por isso, Platão escolhe cinco gêneros supremos: parte do ser, depois estabelece os estados do ser: repouso, movimento e, após detalhada análise diairética, acrescenta os gêneros da identidade e da diferença. (Alguns comentaristas chamam esses cinco gêneros de "categorias" platônicas, inspirados, sem dúvida, nas categorias de Aristóteles).

Platão procura resolver, na constituição de sua ontologia do inteligível, o problema do enunciado negativo, do discurso falso. A negação posta junto de certos termos indica apenas algo "diverso" dos termos. 0 "não x" indica apenas "algo diverso de x". O não justo, o não belo, etc. não negam a realidade em questão, mas apenas afirmam o diverso do justo ou do belo. Desse modo, é refutado o nãoser e a negação como um contrário absoluto do ser, segundo Parmênides, o nãoser não é. Conforme Platão, o não-ser, de certo modo, também é.

Mas se o ser somente pode se expressar no logos, e se o logos pode se manifestar em múltiplos discursos, então é possível indagar pelas condições de uma ciência do inteligível e, ao mesmo tempo, admitir a existência de proposiçōes falsas. A relaçăo entre o ser inteligivel, o uno e o discurso racional leva Platão a perguntar sobre a tarefa do filósofo e a natureza dos sofistas e, conseqüentemente, entre o ser e o parecer, o ser e a linguagem ou o ser e o juízo. Como o estatuto do ser possui caráter relacional, a unidade e a multiplicidade do ser passa pelos gêneros supremos da identidade e da diferença, do outro e do mesmo.

Mais de vinte séculos depois, Merleau-Ponty assume um tipo de reflexão que se propõe reabilitar o sensível e passa a investigar o que ele chama de o ser bruto, selvagem ou pré-reflexivo. O ser aparece como indiviso, latente, transcendente, no sentido rigoroso de "situar-se" numa anterioridade onde ainda não são possíveis as distinções e as fixações entre tipos de realidade e de pensamentos como o filosófico, o mítico, o científico. Essa ontologia, em vez de exigir gêneros ou categorias, requer a prática radical da interrogação filosófica. A interrogação filosófica deverá destruir criticamente todos os conceitos, definições, noções e concepções fixistas ou metafísico-dualistas e ainda indagar pelas origens das relações entre ser e não-ser, ser e parecer, corpo-mundo, corpo-linguagem etc. A ontologia do sensível interroga o ser enquanto visível na opacidade do invisível no sensivel. Ela rompe, supera as categorias tradicionais e até o uso de noções mistas como corpo-sujeito, mundo-carne. Enfim, a questão primordial do ser não é resolvida na dicotomia aprioristica entre sensivel e inteligivel. 
A ontologia pontyana indaga criticamente a emergência categorial da ontologia grega e retorna ao pensamento pré-reflexivo. Enquanto Platão entende o ser como um conceito indefinível e universal e daí alicerça as categorias que fundamentam as questões filosóficas, na perspectiva de um logos do mundo ético, Merleau-Ponty encaminha suas reflexões para um solo mais originário, anterior a todos as determinaçōes, na perspectiva do logos do mundo estético.

Talvez se possa afirmar que a ontologia platônica, para se consolidar como ciência (episteme), só poderia partir de principios inteligiveis. Mas a concepção filosófica de Merleau-Ponty é outra. Para ele a filosofia "não é o reflexo de uma verdade prévia, mas, assim como a arte, é a realização de uma verdade", cabe a ela, em vez de "representar" o mundo, "aprender a ver o mundo" (1994, p. 19). A filosofia, como reflexão radical, não pode partir de postulados. Sendo ela "uma meditação infinita", precisa permanecer fiel a sua intenção, ignorar onde vai, contentar-se com seu essencial inacabamento.

Platão, sem deixar de conceber a filosofia como conduta, postura indagativa, avessa à arrogância, procura o ser ou a idéia que existe em si mesma, por si mesma, simples e eterna (Banquete, $211 \mathrm{~b}$ ), longe das sombras da realidade empírica. Merleau-Ponty, sem se deixar guiar por um racionalismo dogmático, descreve essências repostas na existência, na vida, no cotidiano e não em qualquer superurânio mítico. Quer ver e pensar o mundo antes da reflexăo. Em outros termos, prefere o impasse epistemológico, antes da anterioridade lógico-ontológica das idéias, do a priori do conhecimento.

Para Platão, no Fédon (78 a - 83 b) e na República (507 b), a realidade invisível é constantemente idêntica a si mesma. O mundo sensivel é o mundo visivel, oratón, o que está submetido às mudanças. Esse mundo invisivel é o das idéias divinas e eternas que excluem a possibilidade de qualquer alteração. Os termos eidos, idéa indicam o aspecto exterior, isto é, visível da coisa. Ele não tem uma palavra melhor para apontar formas invisíveis. Em todo caso, a segurança de Platão sobre esse assunto parece tão grande que ele chega ao ponto de apresentar, no Fedro (247 c - d), através de uma linguagem mítica, um lugar supraceleste onde estão as idéias, embora no Timeu, escrito anos mais tarde, ele negue que as idéias ocupem um espaço determinado, conforme testemunha Aristóteles, na Física (203 a).

Platão também adverte, no Fedon (100 b), que a existência do bem, do bom, do grande etc. pode explicar a gênese e as leis ontológicas do mundo físico. 0 problema reside no modo de explicar como as idéias se tornam presentes no sensível, no visível uma vez que o mundo dos fenômenos é cheio de contrários, isto é, existem o belo e o feio, o grande e o pequeno, a verdade e a falsidade. Uma explicação possível disso, no Fédon (100 c), está na teoria da participação, criticada por Aristóteles, na Metafísica (libro I), por não explicar suficientemente a organização do sensivel. A participação talvez seja possível com o recurso à linguagem distinguindo a sinonímia e a homonímia para explicar como as coisas, ao mesmo tempo, participam das idéias e do mundo das coisas. 
Embora Platão, no Parmênides, critique a teoria das idéias, a recepção histónca de sua filosofia ele a aceitou muitas vezes como uma teoria certa. O fato relevante é que no pensamento platônico a unidade é anterior à pluralidade. Em Merleau-Ponty, a unidade é o invisível que se esconde na própria multiplicidade. Dessa concepção resultam diferentes maneiras de explicar o conhecimento. Platão distingue a episteme, da doxa. A doxa é conhecimento sensivel e, portanto, instável. Ao contrário, a ciência conhece o mundo das essências, do permanente, do idêntico. A ciência é ciência do ser. A opinião lida ao mesmo tempo com o ser e o não ser. Daí os juizos da opiniāo poderem ser verdadeiros ou falsos. Nessa perspectiva, o inteligivel, as idéias, o invisivel são um possivel acesso, através da dialética, ao mundo do sensível, como também, através da dialética ascendente, é possível alcançar a essência e o bem. Assim, a linguagem, o conhecimento, tudo é determinado pelo mundo inteligivel. Podem-se afirmar coisas contrárias em relação ao mundo sensível, desde que as idéias permaneçam idênticas a si. As propriedades do mundo sensivel são relativas, contingentes, jamais alcançam o ser, a unidade, a totalidade.

Enquanto Platão explica as relações entre o mundo visível e invisível, apelando para a superioridade das idéias que funcionam como modelo hierarquicamente perfeito relativamente ao mundo sensível, Merleau-Ponty busca, especialmente nos últimos trabalhos, na "noção" carne, a explicação dialética do visível e do invisível. Entre o irrefletido e a reflexão situa-se o corpo e não a alma, no sentido platônico. Na realidade, essa ontologia do sensível pressupõe a crítica à concepÇão intelectualista das essências e até a crítica à análise reflexiva. Ele não fala mais em sujeito nem em corpo, mas em corpo-sujeito e, finalmente, em carne. Esse recurso permite falar de algo anterior ao dito ou expresso pelas teorias ou doutrinas. Primeiro aceita a ambigüidade da linguagem, depois, conforme avança em seu esforço de compreensão, essa ambigüidade é substituída pela reversibilidade. É o ponto onde acabam os hiatos, as distâncias, ou melhor, onde a distância se torna proximidade, e a identidade diferença é a carne, supremo conceito ou metáfora que supera todos os dualismos metafísicos.

O ser, para Platão, é anterior a todo entendimento e a toda a reflexão sobre o mundo. Merleau-Ponty admite que o mundo é o que vemos e, ao mesmo tempo, precisamos aprender a vê-lo. Nessas fórmulas que têm como base a fé perceptiva, encontramos um conjunto de dificuldades, especialmente quando desejamos expressar esse ver "as coisas mesmas" em teses ou enunciados como opera a filosofia em geral. Precisamos indagar "o que é esse nós", "o que é esse ver", "o que é essa coisa ou mundo". As respostas a essas perguntas, como ocorre com o célebre exemplo do tempo em Agostinho, já as temos, mas quando o filósofo passa da percepção para a reflexão e a interrogação, como se nada soubesse daquilo que sabe sua visão, tudo se torna difícil, o mundo natural não é mais reconhecido e instala-se "o secular mau humor contra a filosofia". Nesse sentido, a filosofia precisa evitar todos os acessos pré-determinados, desde os realistas até os idealistas e mesmo os céticos, pois só evitando os preconceitos ontológicos saberemos "o que é o sermundo, o ser-coisa, o ser imaginário e o ser consciente" (1971, p. 15-20). 
O que interessa a Merleau-Ponty é uma ontologia anterior às cisões entre consciência e mundo ou qualquer forma de subjetivismo filosófico e objetivismo científico, de empirismo e idealismo, de dualismo entre corpo e alma etc. É preciso repensar as origens da filosofia. Merleau-Ponty exige a radicalidade da interrogação. A filosofia não pode suspender a reflexão. Sua tarefa não tem fim. Seu ofício é limpar os conceitos dos pressupostos metafísicos.

Essas duas ontologias do inteligivel e do sensivel têm conseqüências nos modos de entender a realidade, o conhecimento e a linguagem. Para Platão conhecimento desdobra-se em graus segundo uma ordem ontológica. A doxa e a episteme e as subformas de conhecimento correspondem aos níveis de realidade representada. A linguagem é predominantemente um instrumento do saber. MerlauPonty mostra que a ciência e a filosofia nunca entenderam a especifidade da linguagem e do conhecimento. A linguagem não é mera tradução do pensamento ou do conhecimento das coisas, mas principalmente expressão e criação de sentido, encarnação de significações, ato de significar. O homem não possui linguagem, ele está instalado na linguagem.

\section{Referências}

DIÈS, A. Parmenide, Théétète, Sophiste. Texte établi et traduit par A. Diès, "Platon, Oeuvres complètes". Paris: Les Belles Lettres, 1974, 1976, 1985.

MERLEAU-PONTY, M. Textos selecionados. São Paulo: Abril Cultural, 1984.

—_. Signos. São Paulo: Martins Fontes, 1991.

— Fenomenologia da percepção. São Paulo: Martins Fontes, 1994.

- Le visible et l'invisible. Paris: Gallimard, 1964.

PLATONE Il Sofista. Texto greco a fronte. Milano: Tascabili Bompiani, 1992. 